\title{
An Integrated Assessment of Community Ecological Based Adaptation (CEBA) Options in Agriculture for Climate Change Adaptation, Resilience Building and Sustainability in Developing Countries: A Case Study of Central Zambia
}

\author{
Stephen Chitengi Sakapaji (Ph.D.) \\ Graduate School of Global Environmental Studies Sophia University, Tokyo Japan \\ $\square$ Corresponding Author: Stephen Chitengi Sakapaji (Ph.D.), E-mail: stevesakapaji@yahoo.com
}

\section{ARTICLE INFORMATION}

Received: 15 October 2021

Accepted: 08 November 2021

Published: 14 November 2021

DOI: 10.32996/jeas.2021.2.2.6

\section{KEYWORDS}

Climate Change, Community

Ecological Based (CEB),

Sustainability, Agriculture,

Resilience-Building, Adaptation,

Zambia

\section{ABSTRACT}

Climate change remains a serious global problem posing a wide range of challenges and impacts which will likely hinder the attainment of the widely discussed sustainable development goals (SDGs). The impacts and threats from a changing climate have the potential to significantly impact all sectors of the global economy and will largely be multifaceted, multidimensional, and multi-sectoral. These adverse impacts will to a greater extent, be manifested at the local and community level where the adaptability capacity is weak and resources are scarce. In the last two decades, there has been growing support and evidence that suggests that local people and communities in partnership with their local governments and NGOs are undertaking community ecological based adaptation (CEBA) practices at both the local and community level which are enhancing their adaptability and resilience capacities to a changing climate. CEBA mechanisms are initiatives and practices that local and rural communities across the developing world are sometimes adopting in partnership with their local government and non-governmental organizations to adapt to a changing climate. However, over the years, these initiatives, experiments, and activities have been poorly actualized, communicated, and there is uncertainty on whether these practices and mechanisms are enhancing the adaptability and resilience capacities of the many poor people in these communities. It is from this background that this paper seeks to assess and analyze present and future climate change impacts on agriculture in Central Zambia and further seeks to appraise the effectiveness of CEBA mechanisms being adopted and utilized in this region. Using community assessment and rural appraisal tools this research paper found that indeed some CEBA practices are innovative and effective and are enhancing the adaptability and resilience of the local people in agriculture in this region. The paper recommends that the advancement, funding, and integration of innovative and effective CEBA practices with scientific knowledge and the ultimate replication and incorporation of these practices into developmental and climate change policies can be one of the most beneficial and effective ways for a sustainable, adaptive, and resilient agriculture sector in the face of a changing and unpredictable climate.

\section{Introduction}

In the last two decades, the reality of a changing climate has dawned on humanity and is now being considered as one of the major developmental issues that are and will continue to challenge local, national, and global sustainability pathways as it has shifted its course from not only being an environmental-based problem but a problem that encompasses the social, economic, and political sphere across the globe. A changing climate is and will continue to present itself as a stumbling block to the attainment of sustainable development pathways, particularly in poorer and developing countries (Rahman et al.,2012; Yohannes, 2016; Wiebe

Copyright: (C) 2021 the Author(s). This article is an open access article distributed under the terms and conditions of the Creative Commons Attribution (CC-BY) 4.0 license (https://creativecommons.org/licenses/by/4.0/). Published by Al-Kindi Centre for Research and Development, London, United Kingdom. 
et al.,2017; Bardati.,2019; Sakapaji,2021). Today, climate change is already making it hard for many countries particularly developing countries, to be able to implement strategies, initiatives, and plans towards achieving the sustainable development goals (SDGs) of the United Nations. In the last decade, millions of people across the globe have fallen victims to the threats and impacts of a changing climate across the globe. Climate change impacts have affected both developed and developing countries. However, the key to note is that the poor or developing countries have and will be affected more due to their vulnerability and the lack of adaptive capacity (Rahman et al.,2012; Bardati, 2019; Sakapaji,2021). The concept of adaptive capacity has been well developed and documented in climate adaptation literature and has mainly focused on its vulnerability (the extent to which a system is physically in harm's way) and sensitivity (how affected a system is after being exposed) to stresses (Adger and Kelly, 1999; Adger et al. 2007; Rashid 2009; Engle 2011; Damodaran 2012; Nyong et al., 2007; Bardati, 2019). The Intergovernmental Panel on Climate Change (IPCC) has extensively used these terms in its many publications with Bardati (2019), defining adaptive capacity as "the capacity or ability of a system to prepare for stresses and changes in advance or adjust and respond to the effects caused by the stresses." Thus, adaptation to climate change is the capacity of a people to be able to respond and implement the necessary measures given by the stress and reduce the vulnerability that comes with it while benefitting from opportunities associated with such changes (Adger et al., 2007; Nyong et al.,2007; Rashid, 2009; Engle, 2011; Bardati, 2019; Sakapaji, 2021).

The last decade has also witnessed growing scientific evidence that shows that climate change is already causing seasonal fluctuations in precipitation and temperature, raising seas level and sea surface temperature, and causing the melting of glaciers, an increase in cyclones and typhoons, forest fires, heatwaves, and floods and these are having a serious impact on the agriculture sector (Shafiee-Jood and Cai, 2016; Yohannes, 2016; Wiebe et al., 2017; Onyutha, 2018). This has prompted government leaders across the globe to quickly reaffirm and agree under the UNFCCC, the 2014 Paris agreement, and the recent 2021 United Nations Climate Change Conference, also known as Cop 26 in Glasgow Scotland to combat climate change, set greenhouse gas (GHG) reduction targets, and reduce the vulnerability of countries and people across the globe. In combating climate change, two prominent strategies have emerged and these are adaptation and mitigation. Mitigation involves the reduction in greenhouse gas emissions as a way to minimize or reduce the impacts of climate change. Adaptation to climate change, on the other hand, involves adjusting to the many vulnerabilities created or brought about by a changing climate so that the systems function well for human beings (Adger et al., 2007; Rashid 2009; Rahman et al.,2012). Over the years, there has been a strong push for mitigation mechanisms to the fight against climate change. However, today research has shown that mitigation alone cannot guarantee us a safe and secure pathway from a changing climate. Many research studies have shown that the adverse impacts emanating from a changing climate will continue to cause havoc in many parts of the globe particularly in the agriculture sector, even if rigorous mitigation measures were to be implemented (Nyong et al.,2007; Damodaran, 2012; Rahman et al.,2012; Anik and Khan 2012; Makondo and Thomas, 2018; Bardati, 2019; Sakapaji, 2021). This realization is also because research and studies have shown that there is an enormous time frame between implementation and results of the many mitigation projects (Rahman et al.,2012). The inadequacies and inefficiency of the mitigation strategy to adequately tackle the current challenges emanating from climate change have pushed many stakeholders across the globe to make the adaptation strategy key in the fight against a continuously changing climate as this strategy has been seen to enhance the resilience and adaptive capacities of many people particularly those in rural and remote parts of the developing world who are vulnerable and projected to be hit hard by climate change impacts.

Agriculture, on the other hand, remains key to socio-economic development in many developing countries. In these countries, the local agriculture sector remains vital for food security by mainly producing the food that people consume. Nevertheless, food security remains a huge challenge for many people globally, particularly in southeast Asia and sub-Saharan Africa, and this challenge is likely going to be exacerbated with the intensity and magnitude of global warming and climate change-related extreme events (FAO 2008; Beddington, 2010; Shafiee-Jood and Cai, 2016; Yohannes, 2016; Wiebe et al. 2017; Onyutha, 2018). Today, approximately 60 percent of the world's population depends on the agriculture sector directly or indirectly, with almost three-quarters of the global workforce employed in the sector (Roser, 2013; OECD and FAO, 2017). Nevertheless, the viability of the agriculture sector depends deeply on favorable weather and climatic conditions. In recent years, the agriculture sector has been threatened by a changing climate that has seen a decline in agricultural productivity in many parts of the globe, especially in developing countries, and this decline has been projected to be severe by 2050 and beyond (Stern, 2007; IPCC, 2007; Shafiee-Jood and Cai, 2016; FAO, 2016; Yohannes, 2016; OECD and FAO, 2017; Sakapaji, 2021). Therefore, measures particularly those to do with adaptation, resilience-building, and sustainability, must be put in place if we are to be able to effectively safeguard the agricultural produce and feed our continuously growing population which is estimated to hit 9.9 billion by 2050 (FAO,2017, World Bank, 2020).

It is from this background that this paper seeks to assess and analyze community ecological-based adaptation (CEBA) options to climate change in agriculture as these have been seen to effectively enhance people's resilience and sustainability efforts to climate change threats and impacts. 


\section{Adaptation in Context}

To begin with, it is important that adaptation is understood in all its forms and how it has emerged as a vital option to the fight against the threats and impacts of climate change before discussing CEBA. Since the beginning of the UN Framework Convention on climate change (UNFCCC), the focus on the negotiating table has always been on the reduction of harmful gases (greenhouse gas) through mitigation mechanisms. Adaptation was always looked at as a supporting option and was never really considered as a vital strategy that can be used to enhance people's resilience efforts and sustainability in the face of a changing climate. Nevertheless, the last two decades have seen a great appreciation and support for the adaptation strategy, with many scholars and researchers acknowledging the role this strategy can play in enhancing the adaptability and resilience capacities of a people particularly the majority poor and marginalized communities across the developing world (Smit and Skinner.,2002; Stern.,2007; Rahman et al., 2012; Anik and Khan, 2012; Makondo and Thomas, 2018; Bardati, 2019; Sakapaji, 2021). As already discussed, adaptation to climate change is the process of coping with the adverse impacts of a changing climate to reduce the vulnerability of a person through enhancing their adaptive capacity (Rahman et al., 2012). According to the Intergovernmental Panel on Climate Change (IPCC), there are three major types of adaptation as discussed in their fourth assessment report and these are:

a. Anticipatory adaptation -an adaptation that takes place before the impacts of climate change are observed and this is also referred to as proactive adaptation.

b. Autonomous adaptation- this is the adaptation that takes place without a conscious response to climatic stimuli but is triggered by ecological changes in natural systems and by market or welfare changes in human systems. This type of adaptation is also referred to as spontaneous adaptation. In this case, a farmer, for example, can decide to change the crop type or planting and harvesting periods to keep up with a continuously changing pattern of precipitation (Rahman et al., 2012).

c. Planned adaptation - this is the adaptation that is a result of a deliberate policy decision based on an awareness that the conditions have changed or are about to change and that action is required to maintain or retain or achieve a desired state (Rahman et al., 2012).

Therefore, adaptation to climate change can be said to be actions, activities, and policies or strategies that can be implemented by people to cope with a changing climate and can be implemented in almost every sector of the economy. Adaptation must be viewed as crucial for most of the least developed and developing countries for a reason being that climate change will hit these regions harder than the developed countries due to their vulnerability and a lack of adaptive capacity (IPCC, 2007; Rahman et al, 2012). Climate change will likely take a toll on the social and economic capabilities of these countries which is likely going to exacerbate the already extreme hunger and poverty situations in these countries and will further hinder the attainment of most of the sustainable development goals of the UN. Adaptation is also a very important strategy in avoiding unwanted impacts of a changing climate in sectors such as biodiversity and it can also be used in restoring and maintaining the ecosystem and its resilience to a single or multiple stresses (Berry et al., 2008; Rahman et al., 2012). In agriculture, adaptation can take various forms. The table below outlines different pathways that adaptation can take place. 
Table 1 Shows Climate Adaptation Pathways in the Agriculture Sector

\begin{tabular}{|c|c|c|c|}
\hline $\begin{array}{l}\text { 1. Technological } \\
\text { Development }\end{array}$ & e & 3. $\mathrm{Fa}$ & $\begin{array}{l}\text { 4. Farm Financial } \\
\text { Management }\end{array}$ \\
\hline 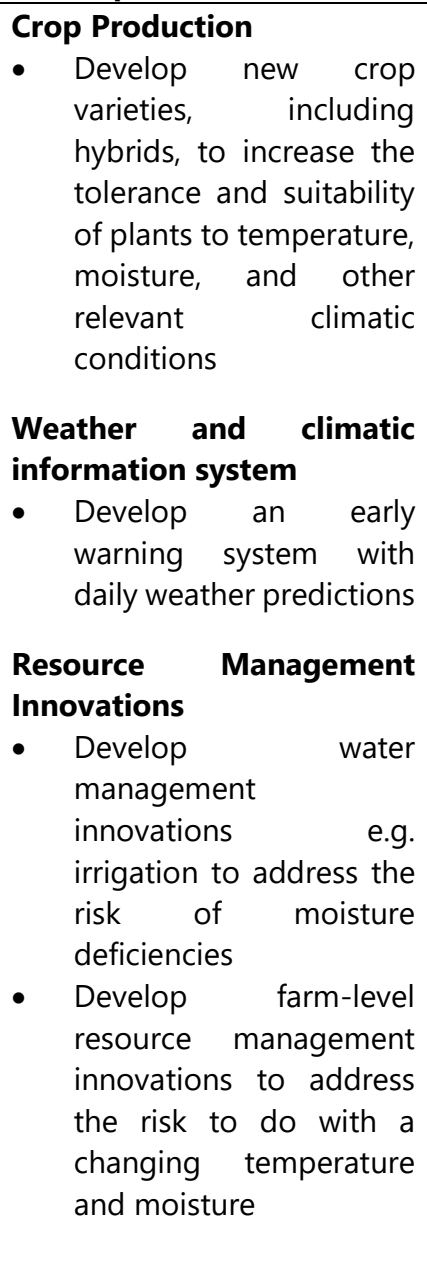 & 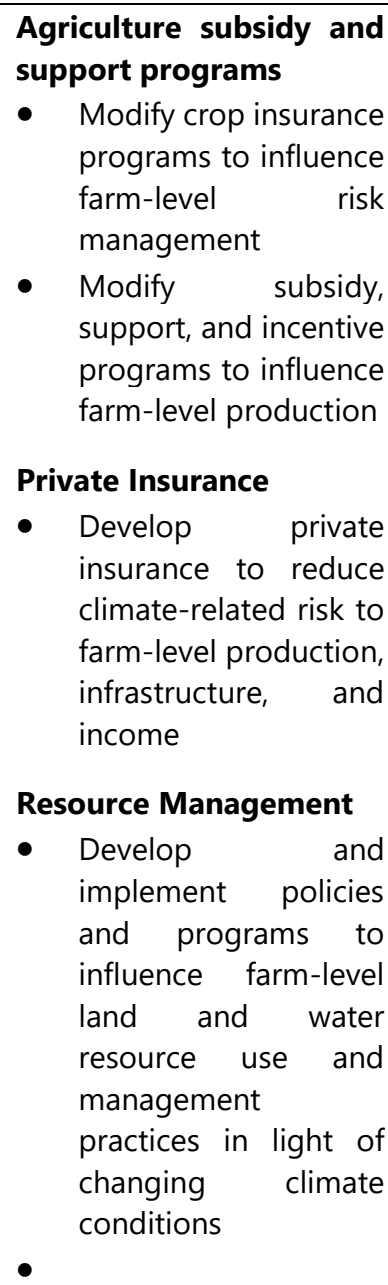 & $\begin{array}{l}\text { Farm Production } \\
\text { - Diversify crop types and } \\
\text { varieties, including crop } \\
\text { substitution, to address the } \\
\text { environmental variations and } \\
\text { economic risks associated } \\
\text { with climate change. } \\
\text { Diversify livestock types and } \\
\text { varieties to address the } \\
\text { environmental variations and } \\
\text { economic risks associated } \\
\text { with climate change. } \\
\text { Change the intensification of } \\
\text { production to address the } \\
\text { environmental variations and } \\
\text { economic risks associated } \\
\text { with climate change } \\
\text { Land Use } \\
\text { Change the location of crop } \\
\text { and livestock production to } \\
\text { address environmental } \\
\text { variations and economic risks } \\
\text { due to a changing climate } \\
\text { Use alternative fallow and } \\
\text { tillage practices to address } \\
\text { moisture and nutrient deletion } \\
\text { due to climate variability }\end{array}$ & 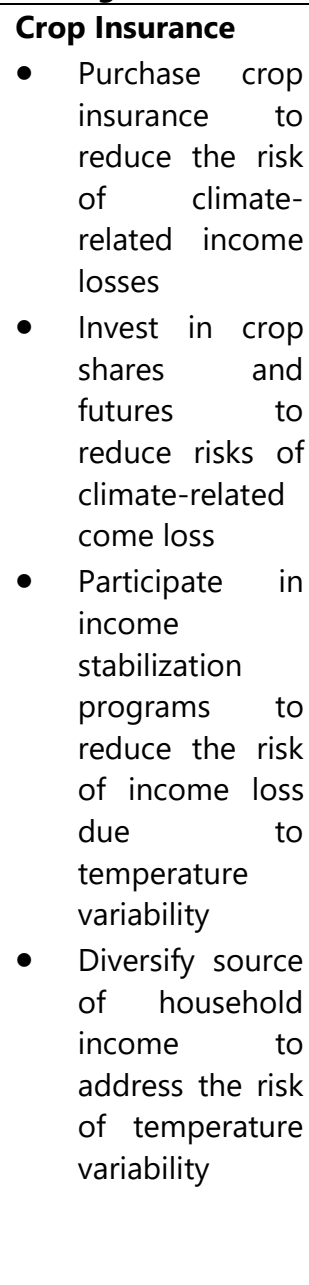 \\
\hline
\end{tabular}

Adapted from: Smit and Skinner, 2002

Adaptation in the agricultural sectors (crops, livestock, forestry, fisheries, and aquaculture) signifies modifying natural, agricultural production, socio-economic, institutional systems, and policymaking in response to and in preparation for actual or expected climate variability and change and their impacts to moderate harmful effects and exploit beneficial opportunities (FAO, 2017). According to Smit and Skinner (2002), in the agriculture sector, adaptation options or pathways can be grouped into four main categories that are not mutually exclusive and these include technological developments, government programs, and insurance, farm production practices, and farm financial management as outlined on table 1. The typology is based on the scale at which adaptations are undertaken and at which the stakeholders are involved. The first two categories are principally the responsibility of public agencies and agri-business, and adaptations included in these categories might be thought of as system-wide or macroscale. Categories 3 and 4 mainly involve farm-level decision-making by producers. Of course, the categories are often interdependent. For example, an adaptation technology developed by the government and the private sector (type 1), might be adopted to modify farm production practices (type 3). Another example could be that a producer may buy more crop insurance (type 4) when this insurance is supplied or subsidized by the government (Smit and Skinner, 2002). However, to date, adaptation research has shown that so far adaptation mechanisms have been sectoral, local, and place-based with little coordination between sectors or between planning and implementation measures. Rahman et al. (2012) have noted that the National Adaptation Program of Action (NAPA), formulated under the umbrella and mandate of the UNFCCC, is an example of sector-based adaptation strategies which focus more on national goals instead of individual communities. Therefore, an effective way to reduce the vulnerability of these countries and their people to climate change would be by mainstreaming adaptation into the existing developmental programs and the involvement of the indigenous, local, and marginalized people and communities as these are the ones to be heavily affected (Nyong et al., 2007; Rahman et al., 2012; Stern, 2007; Makondo and Thomas, 2018; Sakapaji, 2021). Their 
involvement and a sense of ownership of the adaptation program or project empowers them and helps them address pressing climate change issues affecting them at the local level.

\section{Understanding Community Ecological Based Adaptation (CEBA)}

Community ecological-based adaptation (CEBA) to climate change can be defined as an approach to adaptation that allows local people to determine the objectives and means of adaptation practices (Rahman et al., 2012; Forsyth, 2013). It is based upon a participatory assessment of the risks posed by climate change and emphasizes the development needs of vulnerable communities (Rahman et al., 2012). CEBA has been discussed for nearly 20 years now, but there are still tensions about how to implement it or to integrate it more fully within more formal climate change policies. Many international and local organizations, including governments and the International Institute for Environment and Development (IIED), have, over the last two decades attached the highest value to vulnerable communities, actors, and stakeholders to advance adaptation to climate change. CEBA approach has been viewed as effective in helping the local and marginalized communities to effectively deal with climate change threats and impacts and enhance resilience building and sustainability efforts (Rahman et al., 2012; Forsyth 2013; Sakapaji, 2021). The CEBA approach to climate change adaptation seeks to highlight innovative and participatory approaches in the communities that can enhance the resilience and adaptability capacities of the local people to climate change impacts. CEBA has the potential to help poor communities to analyze and assess the causes and effects of climate change in the local contexts. It also seeks to identify the levels of risks and vulnerabilities, integrates local, indigenous, and scientific knowledge in planning appropriate local adaptation strategies and measures that are adaptive, resilient, and sustainable in the long run (Berry et al., 2008; Huq 2008; Miyaguchi, 2011; Rahman et al., 2012; Forsyth, 2013). The aims of CEBA to climate change are more sensitive to the needs and risks faced by poorer, more vulnerable communities. This approach has mostly been associated with the developing and least developed countries of the world. Furthermore, this approach is 'based on the premise that local communities have the resources, skills, experience, local knowledge, and networks to undertake locally appropriate activities that have the potential to enhance resilience and reduce vulnerability to a range of environmental issues including climate change (Dodman and Mitlin, 2011; Rahman et al.,2012; Forsyth, 2013).

The CEBA approach emerged in the early 2000s. Its rise can be attributed to the growing appreciation that adaptation to climate change was necessary and not a distraction from climate change mitigation (Huq, 2008; Rahman et al., 2012; Forsyth, 2013). In addition, local and indigenous communities were also seen to play an important role in natural resource management and thus, their engagement and inclusion in policy formation and the fight against the threats and impacts of climate change were recognized as crucial. The emergence of CEBA was also because before the early $2000 \mathrm{~s}$, practical experience and projects clearly showed that community ecological-based adaptation activities tended to be more effective in addressing community-level vulnerability to climate change and they were sustainable and played a role in natural resource conservation (Forsyth, 2013; Sakapaji, 2021). In most cases, community ecological-based adaptation activities are designed with collaboration and consultation with the local people themselves after the identification of vulnerabilities and needs. CEBA has been viewed as a response to the failures of top-down development models, that have failed to engage with the needs of the most vulnerable members of society (Boyd et al., 2009). Within this mode of thinking, CEBA has the potential to transform power relations between organized groups of low-income citizens, institutions of governance, funding agencies, and international organizations leading to a more effective, empowering, and holistic strategy for responding to climate change (McNamara et al., 2020). Thus, for CEBA to effectively take root practitioners and researchers alike need to take heed of the lessons learned from participatory development and related fields of intervention. In particular, practitioners need not only engage with broader agendas that reduce poverty and vulnerability (Sabates-Wheeler et al., 2008) but also engage with issues of power and governance operating at various scales. As has been pointed out in relation to participatory development, too much focus on the local scale in participation can underplay both local inequalities and adverse power relations at district/city, national and transnational levels (Mohan and Stokke, 2000).

As mentioned above, key in the CEBA approach is the participation of the locals themselves. The full participation of the local people is very crucial because these activities are meant to uplift their living conditions and enhance their resilience to climate change impacts. Their participation also gives them a sense of ownership and these types of projects where the participation of the local people is appreciated are more acceptable since the local people feel their needs are being addressed. In addition, the involvement of the locals allows them to effectively respond to shocks and emergencies rapidly, efficiently, fairly, and ensure that community resources are used economically (Rahman et al.,2012, Forsyth 2013). Besides many experts and researchers have pointed out that the top-down approach to development where communities are not directly involved tend not to address the most vulnerable issues and may end up enhancing their vulnerability (Nyong et al., 2007; Berry et al., 2008; Rahman et al., 2012; Naess, 2013; Forsyth, 2013). CEBA activities have also been seen to enhance awareness and knowledge about climate change and its vulnerabilities among communities even before a project are designed and implemented which is helping in capacity building and education of the most vulnerable communities and can go a long way towards achieving the social development and the sustainable development goals (SDGs) of the UN (Rahman et al. 2012). Thus, the key in CEBA is that the mechanisms must be able to address both the challenges of climate change and the developmental challenges in that specific area. In short, for any CEBA 
mechanism to be considered effective and successful, it must be able to address the most developmental and climate change challenges being experienced in that particular community. Therefore, in assessing the effectiveness of a CEBA project, key questions to be asked would be, has it uplifted the living standards of the people? And has it effectively addressed the greatest climate challenge of the people in that area?

\section{Key Issues to be Considered when Designing and Implementing Effective CEBA Strategies}

a. In assessing vulnerability and the immediate climate change needs of the community, it is important to have a proper understanding of the social networks within the community as they are vital to the success of the CEBA strategies. Thus, when using a questionnaire survey, different questions must be tailored for different groups of people particularly women and the marginalized as they may be faced with similar or different issues that can be key in the implementation of CEBA strategies in that community and which can enhance their resilience and developmental agenda.

b. Any CEBA mechanism must be linked to the local development needs of the community as this has the potential to encourage local and international stakeholders to participate fully, which means that any CEBA initiative or activity must be able to address both the issues to do with climate change and those to do with community development.

c. The appraisal of climate change knowledge and awareness among the local and rural communities is very important for the success of any CEBA activity. This is because many research studies have shown that local and traditional knowledge play an important role in formulating and designing appropriate CEBA tools for capacity building and can enhance the local development agenda.

d. Gaining trust from the local people and community is also very vital for the researchers and practitioners in the implementation of the CEBA projects. This entails spending a lot of time within the community to get to know them fully well. Getting to the community through the already established channels such as those to do with the local government or local NGOs is yet another avenue to pursue that can pave the way to building a relationship with the community. A good relationship will allow for the smooth implementation of the CEBA mechanism that is intended for that community.

\section{Main Steps in the Implementation of CEBA Mechanisms}

The main reasons why CEBA activities are associated with and successful in developing countries is that they are based on the local traditions, beliefs, and practices, involves the entire community, and are relatively easy to monitor, fund, and replicate in other similar ecological ecosystems (Rahman et al., 2012). If properly implemented CEBA adaptation activities or practices are believed to effectively help the most vulnerable communities in addressing and coping with the adverse impacts of climate change by adjusting livelihoods, practices, building capacity, and sharing knowledge (Huq, 2008). Today CEBA has become a popular approach among many environmental and developmental experts as it has been seen as an effective strategy to combating climate change and enhancing resilience and advancing sustainable development. CEBA practices are now being seen as an effective way to simultaneously tackle and address issues to do with social and economic development whilst addressing the local and community challenges emanating from a changing global climate. There are about six crucial steps that must be followed before a CEBA activity can be implemented and the following figure shows these steps.

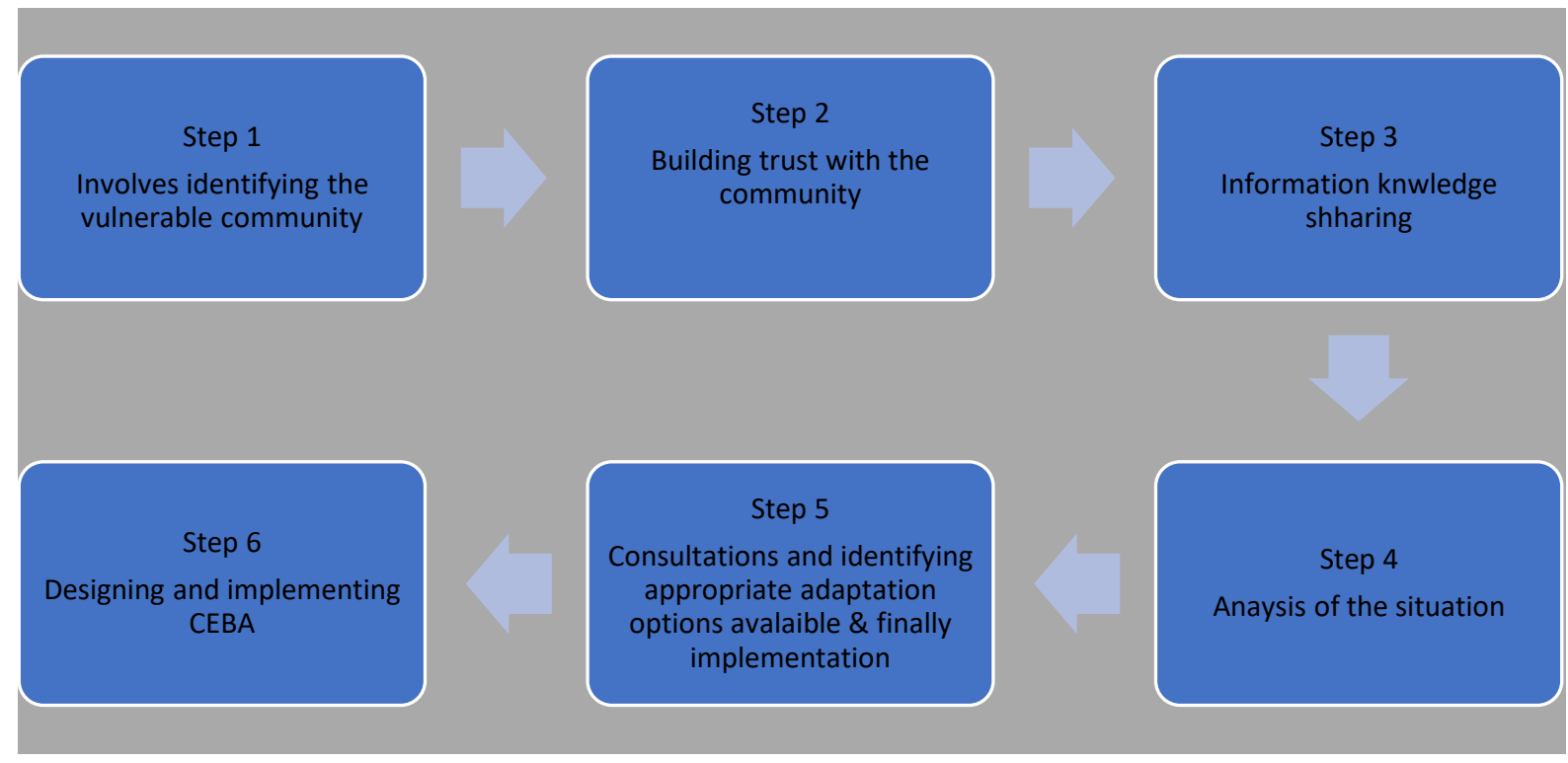

Figure1: Steps in CEBA Adapted from Rahman et al.,2012. 
As mentioned earlier, there are three types of adaptation and these are planned, autonomous, and anticipatory. The above adaptation steps can be referred to as planned adaption because to follow these steps, there is an awareness that the conditions have changed or are about to change and that action is required to maintain or retain or to achieve the desired state. Thus, it is vital to mention that in CEBA some adaptation activities are done spontaneously, and others are planned yet others are done in an anticipatory manner. In the last decade lessons from the CEBA approach have shown that this approach is not theoretically taught in a class but must be practiced. The understanding and knowledge of what CEBA is can only be gained through learning by doing meaning action-orientated (action research). Today networks on CEBA in the developing world have emerged and are being encouraged by many stakeholders including governments and Non-Governmental Organizations (NGOs) and their focus is on knowledge dissemination, knowledge sharing particularly the sharing of the best practices for a resilient and sustainable society for all. Though CEBA practices are still be viewed as being in their infancy stage, progress has been made in many parts of the developing world. There are already a significant number of CEBA projects in various regions of the globe and more are being designed reflecting on the previous ones that have proven to have effectively worked. Over the last few years, the demand for CEBA initiatives and projects has increased among climate change practitioners, NGOs, international agencies, governments, and communities for various reasons among them:

- CEBA practices help to build the adaptive capacities of the most vulnerable poor and marginalized communities who are heavily affected by a changing climate

- The CEBA strategies can also develop and enhance the livelihoods of many poor communities across the developing world

- CEBA initiatives can also be accustomed to fit a specific ecosystem and address vulnerabilities within that particular community

- These initiatives are flexible as they deal with emerging and future climate change threats and impacts

- CEBA projects are often small, and this encourages local participation by the youth, women, local leaders, and the local government and local NGOs

- CEBA projects are, furthermore, easy to design because they are often on a small scale. A group of projects can be designed together to make a larger project without compromising services (Berry et al., 2008; Huq, 2008; Rahman et al., 2012).

Before discussing CEBA options in central Zambia it is vital to point out that long before CEBA activities were featured on many international climate change negotiations and discussions communities around the globe were already implementing small smallscale change adaptation activities in their communities. For a long time now national level NGOs and local level community-based organizations (CBOs) have been the main proponent of community-driven adaptation activities and initiatives (Nyong et al., 2007; Huq 2008; Berry et al., 2008; Rahman et al., 2012). These NGOs and CBOs have been able to upscale the local small-scale activities with science and community training to come up with effective community-level adaptation as observed in Bangladesh and other places in South Asia, Southeast Asia, and Sub-Saharan Africa.

\section{Climate Change and Agriculture in Central Zambia. A Case Study}

Zambia is a landlocked country in the southern central part of Africa with an area of $7752,618 \mathrm{~km} 2$ and a population of 18.38 million people. The country ranks $143^{\text {rd }}$ out of 189 countries on the Human Development Index (UNDP, 2019). Agriculture is one of the mainstays of the economy, employing close to 60 percent of the total labor force, and remains the source of income for most people in rural Zambia (ZCSO, 2018). Maize or corn is the country's staple crop, grown by about 96 percent of the farmers. The average annual temperature in central and southern Zambia is $30^{\circ} \mathrm{C}$, and in the winter (colder season), it can get as low as $5^{\circ} \mathrm{C}$. Rainfall is highest in the northwest, north, and northeast; however, rainfall decreases toward the south, with the southwest where the Zambezi River and Luangwa River valleys are the driest places of the country (NAPA, 2007; ZCSO, 2018). Just like in many parts of the world Zambia is also being impacted by climate change in terms of severe drought, floods, high temperatures, pests, and diseases and this is affecting mostly the poor rural people who solely depend on small-scale farming to feed their families. Zambia is divided into three Agro-Ecological Regions (AERs). This research was conducted in the Chibombo district located in AER Ila (central part of Zambia), as shown in Figure 2. This area was selected because it is predominantly an agricultural area and its one of the agricultural hubs of the country. Furthermore, this region has had practicing small-scale and commercial farming since Zambia's colonial period, making it a suitable place to assess community ecological-based adaptation (CEBA) practices to climate change for resilience-building, and sustainability in Agriculture. 
Figure 2: Research Study Site Location in Zambia

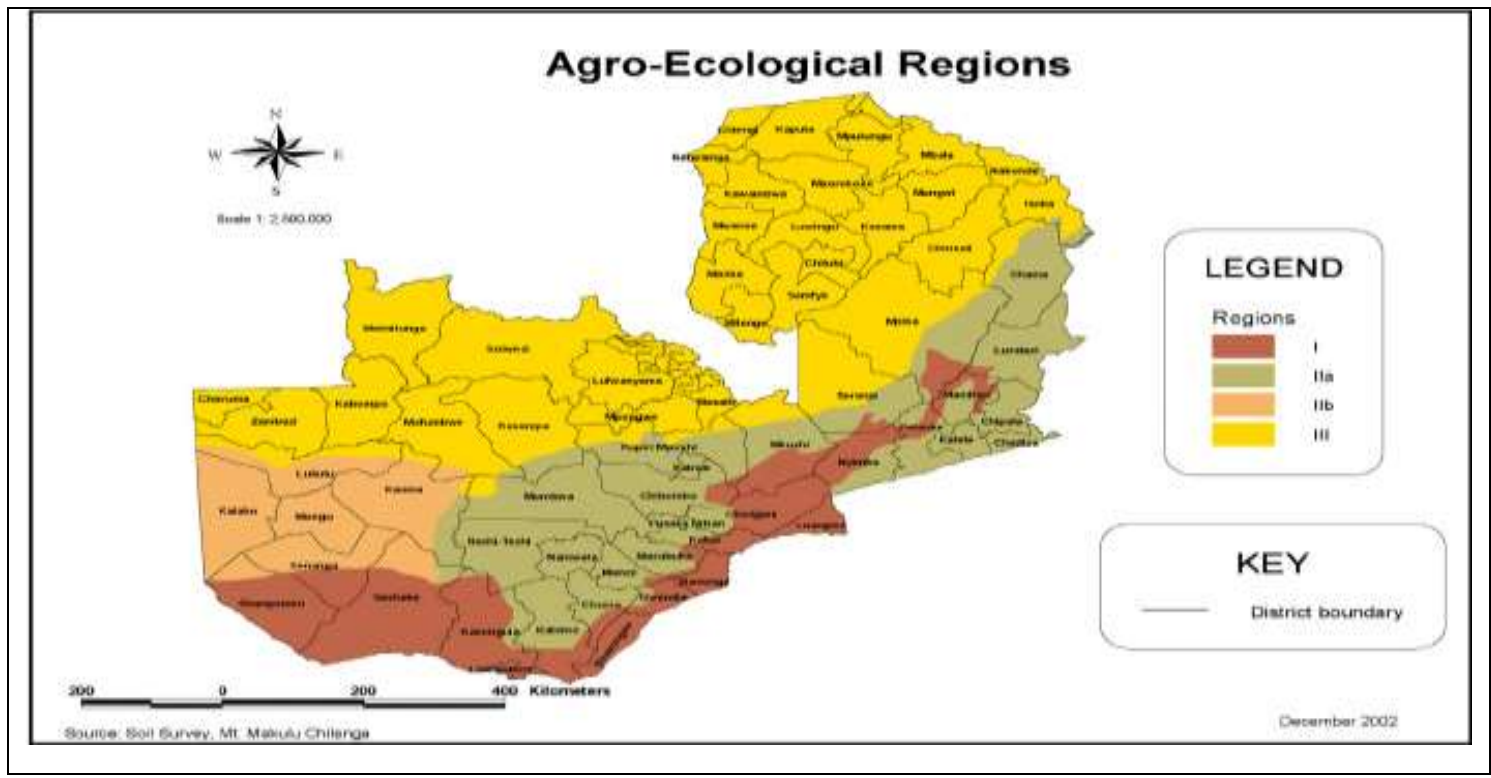

Source: FAO (CFA, Zambian Branch Home Page) 2002

\section{Methods}

This research study used a combination of community risk assessment tools and a range of participatory rural appraisal tools to create an engaged scholarship research paradigm and examine awareness of and capacities for climate change adaptation, resilience-building, and sustainable development. Interviews were core to the data collection. This was supplemented by focus group discussions (FGD) and field observations (transect walks) with the local headmen and extension officers. Oates (2006) argues that a combination of research paradigms or techniques can be used if the research under study is not representative of one research paradigm, and the choice is well justified. Interviews were conducted with one-to-one interaction with the farmers using the questionnaire. Key stakeholders in the field of agriculture, environment, climate, and food security were also engaged in interviews to obtain their views, experiences, expertise, and opinions. The stakeholders targeted in the study were selected based on their skills, knowledge, and responsibility held in the community. The engaged scholarship research paradigm requires the engagement of others from various disciplines who can contribute differently with their unique perspectives and models to understand the problem at hand (Van de Ven, 2007). Engaged scholarship is collaborative and focuses on dialogical action research between academics, practitioners, and the affected community (Van de Ven, 2007; Costello and Donellan, 2012). The engaged scholarship research paradigm inclines and emphasizes that research is and should not be a solitary exercise; it should be a collective achievement (Van de Ven 2007). Thus, engagement means scholars or researchers move out of their inner circle and step outside of themselves to obtain and be informed by others. The choice and use of the engaged scholarship research approach and its related research tools was based on the understanding that the tackling and addressing of any complex social problem requires the engagement and involvement of several actors or stakeholders who possess varying perspectives and expertise for the problem at hand through the various research tools described above (Pettigrew 2001; Hevner et al., 2004; Van de Ven, 2007, 2009; Costello and Donellan, 2012; Gregor and Hevner, 2013; Tweheyo, 2018).

\subsection{Selection of Participants and Research Tools}

This research took place for one month in August of 2019. There was a total of 200 respondents in this research study. Purposive sampling was used for the selection of the participants. The targeted persons in this study were the rural indigenous smallholder farmers. Other participants in this study were the local indigenous leaders, extension officers, research staff, district agricultural coordinator (DACO), and NGOs found in the study locations. The major criterion that guided the selection and participation of these persons in this study was that one had to:

$>$ be a member of the community and engaged in farming activities for a long time

$>\quad$ be a resident of the area for a minimum of fifteen years

$>$ be engaged in the agricultural activities in the area, aware of the challenges faced in the area, and solely dependent on farming activities as the primary source of income 


\subsection{Structured Questionnaires}

The structured questionnaire was prepared with questions that were carefully drafted to fully capture the main underlying issues surrounding CEBA options and how they are being utilized for climate change adaptation and resilience-building in the agriculture sector.

The questions covered areas such as:

$>$ farmers and their family demographic data

$>$ income and background to the farming activities

$>$ challenges resulting from climate change

$>$ CEBA practices being adopted and utilized for adaptation and resilience-building

$>$ source of information required for the adaptation to climate change

In this research, the questionnaires were firstly tested for their validity and a group of students from the University of Zambia took the time to answer the questionnaires to ensure their reliability. After the validation test, the questionnaires were revised accordingly and then administered to the selected respondents from the research study location. The self-administered questionnaire was used in the study because of its advantages in reducing interviewer bias, requiring less time, and facilitating a more leisurely process, which means that more time is given to the respondent to carefully answer the questions (Creswell, 2003; Moyo, 2010). Also, not all the smallholder farmer respondents were willing to be interviewed on a face-to-face basis. Data collected from the self-administered questionnaires were analyzed using SPSS and involved exploring and understanding climate change impacts on agriculture in the study region and the CEBA priorities being implemented by the local people for resilience-building and sustainability. In addition to the self-administered questionnaire, face-to-face interviews were selected for their higher response (Moyo, 2010; Mirembe, 2015). This technique was mainly used to gather information from respondents, such as challenges being experienced in agriculture, climate change impacts on agricultural activities and livelihoods, past and current climate trends, and adaptive local ecological strategies implemented for resilience-building. The targeted respondents were two NGOs, seven researchers, two district agriculture officers (DACOs), who head the two districts. Others include eight extension officers (government officers) and two local leaders. Data collected from face-to-face interviews were analyzed using content analysis to comprehend the local stakeholder farmer's main CEBA used in agriculture to adapt to a changing climate.

\subsection{Focus Group Discussions (FGDs)}

Furthermore, this study also used FGDs which were arranged through the extension officers with different groups of smallholder farmers who did not take part in the self-administered questionnaire interview. This was arranged and completed on separate days to allow the smallholder farmers to prepare themselves in advance. The FGDs were comprised of three groups of smallholder farmers with eleven participants total, five males, five females, and one government official (local extension officer), who assisted with the interpretation of the given questions and validation of the given answers. The discussions were mainly focused on the impacts of climate change on agriculture in the area and the specific CEBA options being utilized for resilience-building in the agriculture sector. The researcher was able to capture the key points of the discussion by taking notes and using a recorder, as some of the farmers were using a local language that the researcher did not understand and required translation at a later stage. Data was collected by notes and a recorder to capture the day-to-day experiences of the smallholder farmers in the study region.

\section{Results and Discussion}

As indicated earlier, the main purpose of this research study was to assess climate change impacts on the agriculture sector in central Zambia and appraise effective community ecological based adaptation (CEBA) options that the local smallholder farmers individually and in partnership with NGOs and local governments are adopting for resilience-building and sustainability purposes. The key was to identify effective CEBA practices the communities are implementing to adapt and enhance resilience in the agriculture sector. In this study, extreme weather conditions, such as severe drought, erratic rainfall, severe heat, high temperature, and floods in some cases were identified to be the most stressful climate-related impacts in this region and have led to several devastating social and economic impacts in this area. In particular, the changing climate has tremendously impacted the lives and lifestyles of the local smallholder farmers in terms of food availability, and this situation has been predicted to get worse as the intensity and magnitude of these extreme events become more prevalent (IPCC, 2018; World Bank 2018; Makondo and Thomas, 2018; Sakapaji, 2021). Furthermore, this study identified erratic rainfall and severe drought as the most pressing climatic challenges in this region in the last decade. These challenges have resulted in food insecurity issues, particularly severe hunger and poverty, for the poor people who form the majority in this region. According to many respondents in this study, the last decade has also seen an increase in temperature, which is causing severe heat and making it difficult to properly engage in agricultural activities. Furthermore, impacts such as drought, erratic rainfall, and severe temperatures have led to the drying up of streams in many parts of central and southern Zambia. 
The findings of this study also indicate that there are seven main pressing social and economic issues emanating from these harsh climatic conditions in the study region, including severe hunger and poverty, diseases, migration, death of domesticated animals, an increase in pests, lack of income sources, and poor health and nutrition. In addition, this study also found that even though this region has experienced and recorded some floods in the last decade, these have not been persistent and severe. The increase in high temperature has been getting worse in the last two decades and this has also been cited in the 2016 Zambia National Climate Change Policy (ZNCCP) (GRZ 2016). The smallholder farmer's respondents acknowledged that climate change is happening as the weather has drastically changed in terms of severe drought, high temperatures, erratic rainfall, floods, and an increase in pests and diseases, especially in the decade, which has made it very difficult for them to do their agricultural activities. Furthermore, ore, the majority of the respondents attest to the fact that high temperatures experienced in the last decade have has led to an increase in pests and diseases both in crops and animals.

In the last decade, the region has also witnessed a sharp rise in crop-eating pests called armyworms, which are causing tremendous loss and stress in smallholder farmers in most parts of Southern Africa. These armyworms are in huge numbers, so much that getting rid of them is becoming difficult, especially for the local poor smallholder farmers in this region who have no resources nor capacities to effectively get rid of these pests. These armyworms eat up the heart or tube of the maize crop at an early stage, leaving it completely depleted and too weak to grow further. This has a huge impact as the maize crop is the staple crop in Zambia and many countries in Southern Africa. Therefore, with the rise in temperature due to climate change, an increase of pests, particularly armyworms, is likely going to lead to an increased negative impact on food security in these regions. In addition to the problem of pests and diseases in the region, the respondents also acknowledged experiencing a rise in the death of domesticated animals, especially cattle and goats. This is due to the severe drought events that the region has been experiencing in the last decade, which has led to a lack of pasture and water. In the last three decades, there has been an increase in severe drought events, with three major drought events occurring in 1991 to 1992, 2006 to 2007, and 2018 to 2019, with the latter leaving approximately two million people across Southern and Central Zambia without food (Voice of America 2019). The negative climate change impacts being experienced in the region have led to the continuous decline in the contribution of agriculture output in terms of goods and services to Zambia's gross domestic product (GDP) for over a decade (World Bank 2018). If this trend continues, the poverty levels in the region will likely be exacerbated, and this will negatively impact the fight against climate change and the pursuit for a sustainable poverty-free society for all.

\section{CEBA Options to Climate Change in Agriculture in Central Zambia}

To adapt to the threats and impacts brought about by a changing climate as discussed above, smallholder farmers in central Zambia individually and in partnership with their local government and local NGOs and local leaders have embarked on community ecological based adaptation (CEBA) options to climate change that they feel have the potential to enhance their adaptability and resilience capacities to the impacts emanating from a changing climate. The following are some of the effective CEBA identified practices in this region that have to effectively enhance smallholder farmers' adaptive capacity in a continuous and unpredictable climate.

\subsection{Conservation Tillage Farming}

Supported by the local government and local NGOs conservation tillage farming is an innovative CEBA practice that smallholder farmers are adopting in this region for climate change adaptation and resilience-building in agriculture. In this study, 44 percent of the respondents indicated that they had used this method of farming in the last decade for climate change adaptation purposes. According to the respondents, conservation tillage farming practices require that there is minimum disturbance to the soils that reduces its compaction and erosion. In conservation tillage farming, small holes or small straight lines are dug early (before the first rain) in preparation for the new farming season. This has the potential to increase soil organic matter and infiltration capacityall of which effectively reduce runoff and enhance climate change adaptation and resilience in drought events, as currently being experienced in the study regions (Haggblade and Tembo, 2003). The minimum disturbance also enables the soils to retain moisture during drought situations and allows crops to grow even with little rainfall because of the moisture that is still trapped in the soil; hence, this practice enhances sustainability. Furthermore, scientists now believe that minimum tillage or conservation tillage has the potential to reduce emissions of $\mathrm{CO} 2$ and other gases stored in the soils because there is little disturbance to the soils (mitigations purposes). By way of comparison, conversion farming involves maximum tillage, which has been found to expose the soil organic matter/carbon to oxidation and makes the soil more susceptible to erosion-both of which result in carbon depletion and less productive soils (Haskett, Simane and Smith, 2019; Haggblade and Tembo, 2003). 


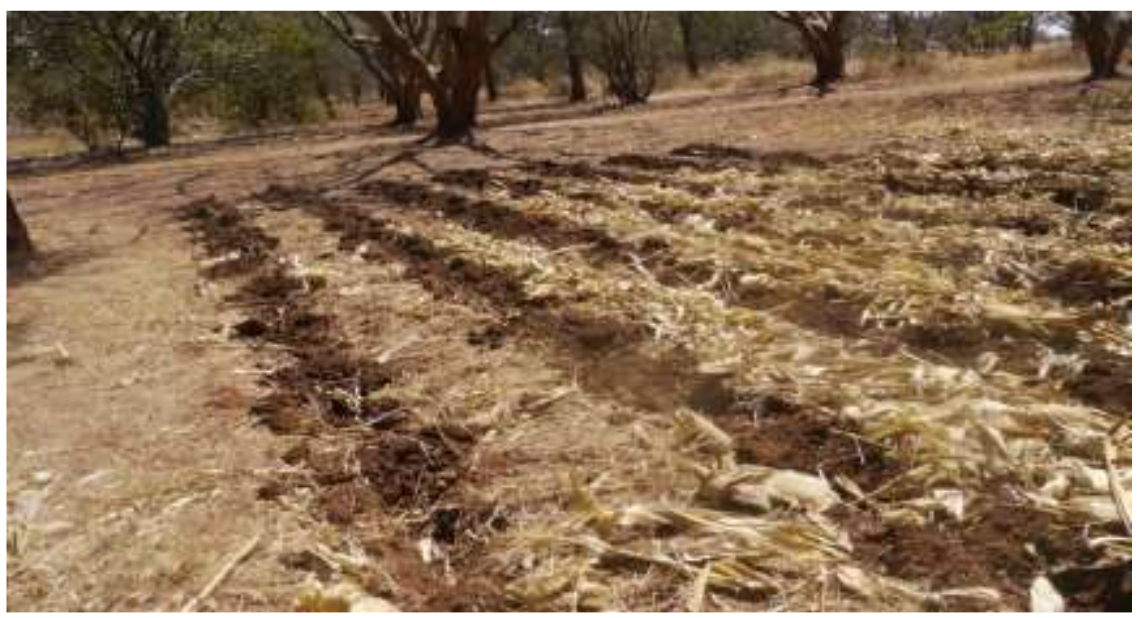

Figure 3: Conservation Tillage Farming in Chibombo Central Zambia Source: Sakapaji., 2021

\subsection{Use of Msango Trees (Faidherbia albida)}

The use of the Msango (Faidherbia albida) trees is yet another effective and innovative CEBA technique being utilized in the study region. In this research study, it was found that 47 percent of the farmers in southern and central Zambia have resorted to planting and using a tree called Msango (Faidherbia albida) for mitigation, adaptation, and resilience-building in a changing climate. According to the farmers in the study region, the Msango (Faidherbia albida) trees have been traditionally used in agricultural activities for many generations in this region and across southern Africa. These trees have been growing in this region for generations, and farmers have always treated them as a blessing whenever they are found on their farms. To the traditional farmers, these trees played an important role as crops planted near them grew tremendously well, and in addition to this, these trees provided pasture for their livestock during the dry season as they shed leaves in the early rainy season and leaf out in the dry season. Because of this unique process, these Msango trees provide both pasture in the dry season and the necessary nutrients to crops during planting time (rainy or wet season). The Msango trees add natural nutrients and organic matter to the soils through the leaf drop, which benefits the crops growing close or under the tree canopy. By doing so, the Msango trees replace the emission of greenhouse (GHG) through the use of Urea fertilizers, which allow for mitigation to take place (Haskett, Simane, and Smith, 2019). Furthermore, the Msango trees increase soil organic matter through the shedding of their leaves in the early rainy season, meaning that the soils can retain the essential nitrogen and moisture for plant and crop growth. Therefore, even if there is erratic rainfall during the rainy season, crops have a chance to grow because enough moisture is retained in the soils under or near the tree canopy (Haskett, Simane, and Smith, 2019). These properties and benefits of the Msango trees have proven essential for climate change adaptation, mitigation, and resilience-building in the agriculture sector in this research study region and other places in East Africa, such as Ethiopia (Haskett, Simane, and Smith, 2019). In central, eastern, and southern Zambia, farmers are now being encouraged by the local NOGs and local government to use both Msango trees and conservation tillage farming to harness the many benefits that are associated with these practices.

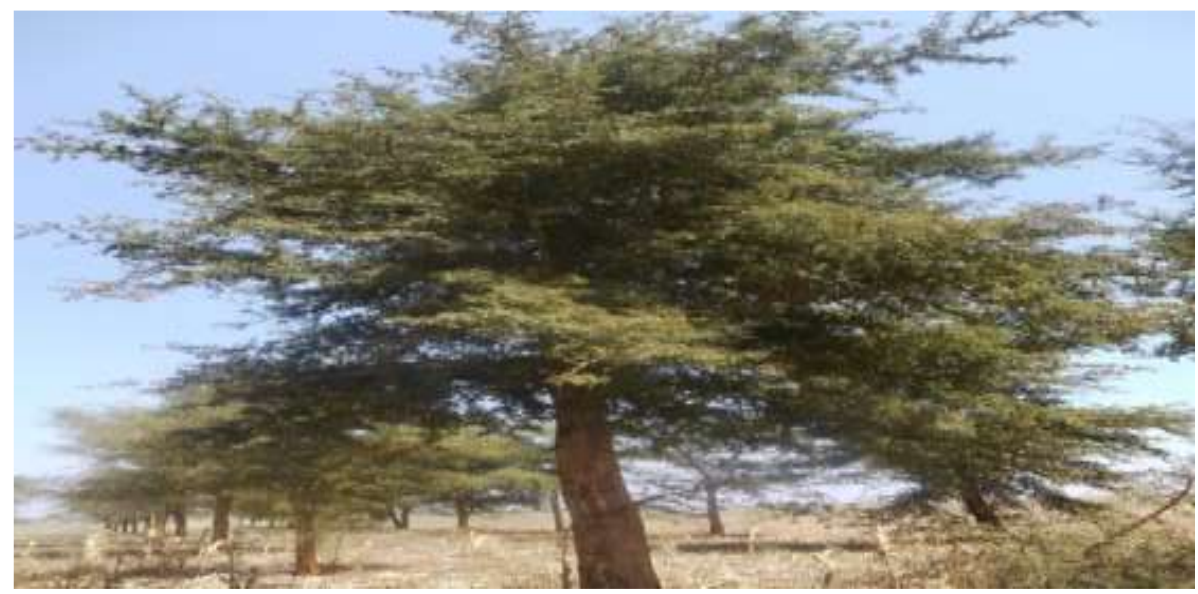

Figure 4: Msango (Faidherbia albida) Trees Planted on a Farm to Harness Many Benefits Source: Sakapaji.,2021 


\subsection{Crop Rotation with Legumes and Intercropping}

Crop rotation with legumes and intercropping is yet another CEBA strategy that is being encouraged and adopted encouraged and implemented in this region. In this study, 38 percent of the respondents acknowledged using crop rotation and intercropping with cover crops and legumes, such as beans and peanuts, for adaptation to both drought and floods. This practice of intercropping and crop rotation is utilized by local and indigenous people across the globe (Altieri and Koohafkan, 2008; Anik and Khan, 2012; Awal 2014). In this study, such practices were common before the Europeans came to the area (Mulemba 2009). Indigenous and local people in the area would rotate crops once in a while and also intercrop them for better yield. However, in the face of climate change, science has expanded this knowledge by looking deep into the real benefits that come with such practices. For many indigenous and local people, the reasoning behind these practices was purely seen from the perspective of higher productivity rather than the scientific explanation of it. Science has explained that crop rotation is useful for reducing soil carbon when compared to continuous cropping, which has the potential to increase carbon levels in the soil; the former qualifies this as a sustainable agricultural practice (Altieri and Koohafkan, 2008; Anik and Khan, 2012; FAO 2014). Legumes, such as beans and peanuts, and crop covers, such as wheat, barley, and oats, have also been found to enhance both soil fertility and soil organic matter (FAO 2008). Besides, these crops tend to play a vital role in ensuring that the soil is protected during intense rainfall events by absorbing most of the raindrops and, thus, reducing soil erosion and nutrient depletion during runoff (Altieri and Koohafkan, 2008). These crops also protect the soil during periods of drought as they protect the topsoil from wind erosion. Crop rotation, whether taken in a five- or two-year interval, has the potential to reduce pest pressure, increase soil recovery, and enhance a field's crop production capacity (Altieri and Koohafkan, 2008; Haskett, Simane, and Smith, 2019). These practices can be useful, especially in a changing climate and in the pursuit of sustainable practices in the agriculture sector, and thus, it is reasonable that their use is encouraged.

\subsection{Diversifying Crops and Income Sources}

From the research study, it was found that 97 percent of the farmers are diversifying their crops and income sources to adapt to the changing climate. The diversifying of crops and income sources to adapt is yet another CEBA option that is being adopted by the local smallholder farmers in this area. Being a region that has solely depended on cultivating one crop (maize), diversifying of crops requires that farmers plant many different crops so that when one fails due to climate change-related events, the other crop can act as a replacement because different crops react differently to a changing climate (Anik and Khan 2012; Awal 2014). It is the understanding of the smallholder farmers and the local and international NGOs in this area that diversifying crops has the potential to help the farmers harvest something even when climatic events hit hard. The diversifying of crops and income sources has also been cited by other research studies, such as Nyong, Adesina, and Elasha (2007), Anik and Khan (2012), Awal (2014), and Rahman (2016). Diversifying income sources requires that one engages in other income-generating activities apart from farming to adapt to climate change, and these include a shift from farming activities to charcoal burning, as found in this study. Gardening in former streams and charcoal burning were prominent alternatives in this research study. However, the charcoal burning activity is harming the environment, as observed from the drying up rivers in the area due to an increase in deforestation (Kalinda et al. 2008). As the world is pushing for sustainable pathways this practice means then that another alternative income-generating activity that is sustainable and environmentally friendly must be found to replace charcoal burning. As an adaptation option to a changing climate by the local people in this region, the diversifying of crops and income sources needs to be supported by the local government and its developing partners ( $\mathrm{NGOsO}$ as this is giving life to a people who are desperate to find means to adapt in a changing climate.

\subsection{Planting with First Rains, Early Maturing Varieties and Local Drought-Resistant Crops}

Due to the erratic rainfall that the study regions have experienced in the last decade, the local smallholder farmers have resorted to planting with the first rains as it is hard to predict how long the rainfall season will last as before. This is in line with research studies in other different parts of the globe where such a practice has been seen to enhance the adaptability capacity and resilience of the local people in a changing climate (Awal, 2014; Anik and Khan, 2012; Makondo and Thomas, 2018). In this research project, more than 90 percent of the smallholder farmers in this study acknowledged that they are now forced to plant early (with first rains) due to the continuous erratic rainfall in the area. Furthermore, 88 percent of the respondents also acknowledged using their local drought-resistant crops, such as sorghum and other local maize varieties, in enhancing and building resilience in a volatile and changing climate. The reasoning behind planting early or with first rains is that you enhance the chances of that crop to successfully grow, especially if you plant early maturing varieties of maize crop, such as MM 601 and MM 603, which have been recommended by the government extension officers, local NGOs and the conservation farming unity of Zambia. Planting locally drought-resistant crops, such as sorghum, with the first rains also enhances the chances of that crop growing even if the rains do not continue to fall. It is therefore vital that rigorous research is undertaken in the development of varieties of crops that can suit a changing climate as this is the only way the local smallholder farmers in this region can adapt and build resilience in the agriculture sector. 


\section{The Sustainability of CEBA Activities in Central Zambia}

In this study, the sustainability of these practices will mainly be dependent on the changes to climate events over time. Thus, the sustainability of these CEBA practices will largely depend on future climate change events in the region which means that upscaling and modifying these practices could be the best possible way to guarantee the smallholder farmers of a continuous adaptive and resilient agriculture sector. Furthermore, this study found that the locally funded initiatives, those implemented by NGOs, those focused on climate-awareness raising and those integrated with the local knowledge performed well and proved to be effective in enhancing the adaptability, resilience, and sustainability capacities of the agriculture sector and that of the local poor people to climate impact in the region. This study also found that integration and collaborative learning between local and scientific knowledge in learning about climate change impacts in the region and possible adaptation mechanisms may be critical for optimizing adaptation as can be seen from the use of the Msango trees. Because livelihoods in this region just like many rural communities are inextricably linked to local ecosystems it was found that it is imperative that the understanding of these connections and elements within and across communities is well known to be able to design and implement and establish effective CEBA mechanism. Despite high performances among these initiatives at the time of this study, it is critical to remember that longterm improvements in adaptive capacity and vulnerability will become clearer over time and will depend on the changes in the climate of this region.

These CEBA options and practices identified and discussed in this research study have proven to effectively enhance the adaptability and resilience capacities of the local smallholder farmers in this region to the climate change pressures of the twentyfirst century. Furthermore, in all the CEBA options discussed in this research, you can see the collaboration between the local communities and the local government and between the local NGOs and the local communities which is a key ingredient in any effective CEBA practice. However, even though the discussed CEBA options in agriculture in central Zambia have proven to effectively enhance the resilience and adaptive capacities to climate change impacts of the local smallholder farmers in this region, it must be noted that there are many challenges in seeing to it that CEBA strategies take root in rural communities across the developing world, as such it is imperative that these challenges are discussed, and the way forward outlined.

\section{Challenges of Implementing CEBA Activities}

- Time Consuming and difficult to achieve without investment in time and learning. The implementation of CEBA strategies requires careful deliberations of both the local considerations and projections of climate change from known climate models (Huq, 2008; Berry et al., 2008; McNamara et al. 2020).

- There is also a thin line between activities that are solely meant for development and those that are meant for fighting climate change. This has proved to be a huge challenge to many donors seeking to see immediate results of the project they are investing in, and it has proved difficult to assess the outcome of such a project in clear demonstrated terms.

- Research has also shown that the many so-called mechanisms have been done haphazardly by many local and intergenerational NGOs for the sake of receiving funding and have ended up even causing more harm to the people than planned. Many of these activities are implemented within a short period and without well-researched climate change vulnerabilities and adaptation priorities in that area. These types of CEBA initiatives have resulted in mal-adaptation and have in some cases resulted in the misunderstanding between the communities and the CEBA implementers or practitioners (Rahman et al., 2012; McNamara et al., 2020).

- CEBA approach just like many other disciplines such as development covering community-related research rests on the assumption of the existence of "communities" as small-scale human groupings bound socially by a common cultural identity, living within defined spatial boundaries, interacting on a personal rather than bureaucratic basis and having an economic interest in the common pool interests of the area (Miyaguchi, 2011). However, such examples rarely exist in areas that are culturally heterogeneous, economically stratified, whose boundaries are porous, and where social cohesiveness is fragile (Murphree 2000). "Community" in such cases is elusive and is characterized as much by internal differences (in the priorities, needs, vulnerabilities, and capacities of the people) as by commonalities (Reid et al., 2009). Therefore, treating and recognizing a community as one static target for CEBA may create a serious gap in understanding between the project developers and the members of that community. Thus, care and serious consideration must be acknowledged when researching, designing, implementing, and upscaling a CEBA project or program.

- The call for the local government to be a facilitator in CEBA initiatives rather than giving directives is yet another challenge that CEBA implementation can face. This is because achieving this goal is time-consuming, at best and at worst where there is no dedicated discussion of where CEBA leads to in terms of the devolution. In this vein, there have been discussions indicating there is remains a risk that CEBA will merely be a short-lived fad among the development bilateral/multilateral agencies and will fail to put the poor rural people in the driving seat (Miyaguchi, 2011; McNamara et al., 2020). 
- Scaling up CEBA initiatives is yet another challenge that can easily be faced by practitioners and implementers. Over the years there have been many attempts to take successful CEBA initiatives and scale them up worldwide, but this has proven problematic. Thus, while CEBA initiatives are increasing in number and information about the activities is being gathered and shared, it remains a challenge to translate this into improved policy responses and initiatives that can be implemented worldwide (Reid et al., 2009; Rahman et al., 2012). The rosiest picture is for adaptation to take place across a much wider area while being rooted in the reality of small-scale community livelihood situations. Even though the synthesis between the global implementation of an adaptation program and community-based adaptation activities is the ultimate goal of CEBA, such synthesis is often too difficult in reality.

- The specific funds mandated under the UNFCCC present another additional challenge related to proving that interventions respond to climate change (and not broader vulnerability to climate variability), and therefore these funds maybe even less effective in dealing with the real challenges at the local level (Ayers, 2009)

- Inadequate monitoring and funding can present another challenge to the successful delivery of CEBA because communitybased and civil-society monitoring are essential to ensure the appropriate resources reach the most vulnerable communities (Miyaguchi, 2011; McNamara et al., 2020). Monitoring of planned activities is crucial at the community level. A national stakeholder forum will require regular written and field-monitoring-visit reports to enable governments to be held accountable to the funding body (Ensor and Berger, 2010). However, this is much easier said than done. In many cases across the developing world, there has been a clear absence of monitoring activities which has resulted in minimal reporting of progress or evaluation activities to the central level of management. This is because the CEBA projects in each country are owned and participated in by community members and respective non-governmental and community-based organizations. Their involvement often means the projects need much more time than the original schedules allowed. The issue of participation can also be problematic. Reid et al. (2009) have shown that the priorities and interests of outsiders often override those of communities and that communities tend to be imposed upon rather than empowered to take control. But at the same time, adaptation can only be effective and sustainable when it can draw on the knowledge and priorities of local people, build on their capacities and empower them to make changes themselves.

- As it is well known today CEBA differs from other community-based work in that it must incorporate difficult climate-sciencerelated scenarios and projections into a localized prioritization and planning process (Miyaguchi, 2011). Since, in general, there is very little awareness of climate change at the grassroots level, incorporation from above (or at least from outside) must be done. Where outside agencies are driving this agenda, they can find themselves transmitting information in a top-down manner that goes against the tenets of CEBA (Van Aalst et al., 2008). This is a highly sensitive issue for which no one has yet proposed a clear solution and as such more research is required to be able to clarify these matters that are key to the successful progress of CEBA in developing countries.

\section{Recommendations}

Drawing from the above-discussed challenges recommendations must be outlined to make the call for CEBA a reality. The following are some of the recommendations that have been seen fit to strengthen the call for CEBA activities and see to it that the sustainability, resilience, and adaptive capacities of the local poor people in the developing world is enhanced and their quest for development that is inclusive, adaptive, and resilient is attained.

- It has been observed by many researchers and scholars that rather than doing experiments that seek to improve the adaptability and resilience capacities of these poor communities it would be better if these communities would lead these adaptation priorities, building on their strengths and design or drive their adaptation actions based on their local knowledge, experiences, and coping mechanisms. It has been acknowledged that when communities lead their adaptation agendas, numerous aspects of the optimization points would likely be autonomously incorporated: the most pressing climatic and nonclimatic livelihood pressures in the relevant system would be equally prioritized and considered; context will be underpinned which means important resources, knowledge and contextual factors are and will be more appropriately utilized; and a stronger sense of local approval and ownership will be fostered (McNamara et al. 2020). Thus, understanding and following these outlined factors has the potential to support sustainability which is key in adaptation, and which requires improvement as can be seen from the research case study. Adopting these issues mentioned here would foster initiatives that are a community rooted comprising of aspirations and local context, which will be self-sufficient over time (Nuun \& Kumar, 2019; Korovulavula et al., 2019).

- Furthermore, implementers' and donors' roles in the advancement of CEBA initiatives should be that of being 'facilitators or 'co-designers of the desired adaptation aspirations for communities, rather than 'doing' adaptation 'to communities' under 
the guise of bringing development to the rural communities. By doing this the implementers would support and empower 'communities' in their diversity of expressions and guide them in certain processes (e.g., in supporting shared adaptation in terms of access and benefit or empowering women in leadership positions). Through local government and the facilitators monitoring and guiding the resources and supporting participatory processes with holistically targeted equity framings, and a deeper understanding of any contextual misunderstandings related to inequality and power may overcome critiques the of CEBA approach. Ultimately the role of implementers and donors is to prepare and support communities to lead $r$ own adaptation because, as we have seen, implementers have left not long after the project has been implemented, and funding may ultimately dry up (McNamara et al., 2020).

- The need to broaden the awareness of all aspects and elements that comprise a community must be well known by all practitioners, donor communities, and the local government.

- Involving poor groups in CEBA for both mitigation and adaptation can transform the broader political relationships in which they are involved (McNamara et al., 2020). However, for this to occur, CEBA needs to include tools and methods that enable a more explicit transfer of power to local communities, as otherwise, decisions are made by those outside the community who are only partially or not at all accountable al residents. Thus, to achieve this requires an engagement of all stakeholders including the local government, and with international development agencies and donors.

- This research also recommends that innovative financing mechanisms, are put in place as the existing funding structures and systems of the official development assistance over the years had always made genuine local and community engagement impossible and difficult.

- Greater emphasis needs to be also put on representative organizations withstand be local or international but work with the local communities to be able to link and equip these low-income and disadvantaged communities with tools and knowledge that may help them to deal with the multiple scales of impact and/or intervention. Specific attention should be given to the interface between climate change priorities alongside other immediate development needs, and the heterogeneous needs within low-income households and neighborhoods (McNamara et al., 2020).

\section{Conclusion}

This research endeavored to explore and assess climate change impacts on the agriculture sector in central Zambia and further appraise the community ecological-based adaptation (CEBA) options that the local smallholder farmers are adopting and implementing for resilience building and sustainability. The findings of this study indicate that climate change is and will continue to cause negative impacts on the agriculture sector in this region and this will tremendously impact the social and economic status of the poor and rural people in this region and will further exacerbate the already high poverty and hunger situation in the area. Climate change-related impacts such as drought, erratic rainfall, high temperatures, and floods were found to be prevalent in this region and will continue to devastate the livelihoods and lifestyles of the many poor people in this region who solely depend on nature-based activities for survival. This research was also able to identify effective CEBA options which are being adopted and implemented by the local smallholder farmers. Tapping from the local people's knowledge of their local ecological system, the local NGOs in partnership with the local government are setting up adaptation mechanisms that are effective, resilient, and sustainable. Among these is the use of the Msango trees for mitigation and adaptation purposes, diversification of income and crops, planting with the first rains, crop rotation with legumes, conservation tillage farming. These practices play an important role in enhancing the adaptability, resilience, and sustainability efforts of the smallholder farmers in these communities. Therefore, in as much as many scholars and researchers claim that CEBA mechanisms have not yet taken a positive direction that its initial supporters would have imagined these practices are offering significant advantages in making adaptation interventions more relevant to vulnerable people, and by considering the range of social, political, and economic factors that drive vulnerability. As can be seen from this study, these CEBA options can reduce vulnerability more directly and increase the likelihood of success of adaptation interventions. Despite the recorded success of some CEBA options, including the ones discussed in this research, it must be acknowledged that CEBA as an approach has its share of challenges as discussed in this research which needs to be, acknowledged and whose existence may hinder the development, direction, and effectiveness of this seemingly new approach in the pursuit for development that is sustainable, adaptative and resilient to climate change impacts. It is in this vein that, there is a need for proper coordination between all stakeholders (donor community, funders, local governments, local communities, and local NGOs) in the designing, implementation, adoption, and monitoring of these CEBA activities. In doing so the livelihood of the many rural and poor communities across the developing world would be safeguarded and their quest for development that is sustainable, adaptive, and resilient, and which addresses their immediate needs would be achieved.

It is, therefore, extremely important that CEBA as an effective approach to the pursuit for an adaptive, sustainable, and resilient community forms part of a wider trend of new thinking about adaptation to climate change that integrates international 
development and climate change policy to achieve more resilient and socially inclusive forms of growth. It is also important to understand that despite the supposed development deficit that has always been projected on the local and poor communities across the developing world these communities have always been resilient and there is still much that practitioners, implementers, and the donor communities can learn from traditional governance systems and Indigenous and local knowledge systems. This research and its findings suggest that local and indigenous people have for centuries supported their diverse capacities and have adapted to change within their local environment using local tools and resources; therefore, what is needed is collaborated support to enhance these local efforts that they know too well. The future and success of CEBA, therefore, might not depend on emphasizing specific local examples across the developing world, but in demonstrating how participatory and deliberative risk assessment and interventions can reveal the importance of social vulnerability to climate risk, and a wider range of possible adaptation options.

Funding: "This research received no external funding"

Acknowledgments: Sincere appreciations go to all the stakeholders who participated in this research study, especially the smallholder farmers whose information was vital to the execution of this research study.

Conflicts of Interest: "The author declares no conflict of interest."

\section{References}

[1] Adger, W. N., Shardul A., Cecilia C., Karen O., Juan P., Barry S., and Kiyoshi T. (2007). Assessment of Adaptation Practices, Options, Constraints, and Capacity. Contribution of Working Group II to the Fourth Assessment Report of the Intergovernmental Panel on Climate Change, edited by M. L. Parry, O. F. Canziani, J. P. Palutikof, P. J. van der Linden, and C. E. Hanson, 717- 743. Cambridge University Press. https://www.ipcc.ch/site/assets/ uploads/2018/02/ar4-wg2-chapter17-1.pdf.

[2] Adger, W. Neil, and Mick P. Kelly. (1999). Social Vulnerability to Climate Change and the Architecture of Entitlements. Mitigation and Adaptation Strategies for Global Change 4:253-266. https://doi.org/10.1023/A:1009601904210.

[3] Altieri, M. A., and Parviz K. (2008). Enduring Farms: Climate Change, Smallholders, and Traditional Farming Communities. Third World Network, 1-72. http://agroeco.org/wp content/uploads/2010/11/Enduring-farms.pdf.

[4] Awal, A. (2014). Water Logging in Southwestern Coastal Region of Bangladesh: Local Adaptation and Policy Options. Science Postprint 1 (1): e00038. https://doi.org/10.14340/spp.2014.12A0001.

[5] Ayers J, Forsyth T. 2009. Community-based adaptation to climate change: strengthening resilience through development. Environment, 51:22-31.

[6] Awuor, P. (2013). Integrating Indigenous Knowledge for Food Security: Perspectives from Millennium Village Project at Bar-Sauri in Nyanza Province in Kenya. Paper presented at the International Conference on Enhancing Food Security in the Eastern and Horn of Africa Regions, Kampala, UG, November 16-17, 2011. https://elibrary.acbfpact.org/cgibin/ acbf?a=d\&d=HASH0125f03e14754cc7afe40524\&gg=0.

[7] Bardati, D. (2019). Participatory Agroecological Assessment of Farmers' Capacity to Adapt to Climate Change in Malawi. International Journal of Climate Change: Impacts and Responses 11 (3): 15-33. https://doi.org/10.18848/1835-7156/CGP/v11i03/15-33.

[8] Beddington, J. (2010). Food Security: Contributions from Science to a New and Greener Revolution. Philosophical Transactions of the Royal Society of London B 365 (1537): 61-71. https://doi.org/10.1098/rstb.2009.0201.

[9] Berry, P.M, Paterson, J, Cabeza M.,Dubuis, A., Guisan, A.,Jaatela , L .,Kuhm, I .,Musche,M.,Piper.,J and Wilson E . (2008). Adaptation and Mitigation Measures and their Impacts on Biodiversity. Minimization of and Adaptation to Climate Change: Impacts on Biodiversity (MACIS) Report. Dhaka.

[10] Boyd, E. \& Tompkins, E. L. (2010). Climate Change. A Beginners Guide. One world.

[11] Costello, G, and Brian Dn. (2012). Engaged Scholarship in the Innovation Value Institute. Paper presented at the Irish Academy of Management Conference, September 6-7, 2012, National University of Ireland. Maynooth

[12] Creswell, W. John. (2003). Research Design; Qualitative and Quantitative Approaches, 2nd ed. London: Sage Publications.

[13] FAO (CFA, Zambia Branch homepage). Found at: https://www.researchgate.net/figure/Zambia administrative-boundaries-and-agroecological-regions-I-Ila-IIb-III-Amount fig1 262987499:

[14] Damodaran, A. (2012). The Economics of Coping Strategies and Financing Adaptation Action in India's Semi-Arid Ecosystems. International Journal of Climate Change Strategies and Management 4 (4): 386-403. https://doi.org/10.1108/17568691211277728.

[15] Dodman D, Mitlin D. (2011) Challenges for community-based adaptation: discovering the potential for transformation. J Int Dev 2011 Wiley Online Library, 2011.

[16] Donatti, C. I., Celia A. Harvey, M. Ruth Martinez-Rodriguez, Raffaele V, and Carlos M R. (2019). Vulnerability of Smallholder Farmers to Climate Change in Central America and Mexico: Current Knowledge and Research Gaps. Climate and Development 11 (3): $264-286$. https://doi.org/10.1080/17565529.2018.1442796.

[17] Engle, N. L. 2011. Adaptive Capacity and its Assessment. Global Environmental Change 21 (2): $647-656$. https://doi.org/10.1016/j.gloenvcha.2011.01.019.

[18] Forsyth, T. (2013). Community-based adaptation: A review of past and future challenges. Wiley Interdisciplinary Reviews: Climate Change. 4. $10.1002 /$ wcc.231.

[19] FAO (Food and Agriculture Organization of the United Nations). (2008). Climate-Smart Agriculture: Policies, Practices, and Financing for Food Security, Adaptation and Mitigation. FAO. 
[20] GRZ (Government of the Republic of Zambia). (2016). National Climate Change Policy. Ministry of Lands Natural Resources, and Environmental Protection.

[21] Gregor, S, and Allan R. H. (2013). Positioning and Presenting Design Science Research for Maximum Impact. MIS Quarterly 37 (2): $337-355$. https://doi.org/10.25300/MISQ/2013/37.2.01.

[22] Haggblade, S., and Gelson T. (2003). Conservation Farming in Zambia. International Food Policy Research Institute.

[23] Hagemann, M., Frauke U., Otto L. N., and Hendel S. B. (2012). Planning Climate Compatible Development: The Role of Tools and Methodologies. CDKN.

[24] Harmeling, S. 2011. Background Paper on Integrating Adaptation and Mitigation in the Agricultural Sector. Bonn, DE: German Watch.

[25] Haskett, J. D., Belay S, and Caitlin S. (2019). Energy and Climate Change Mitigation Benefits of Faidherbia albida Agroforestry in Ethiopia. Frontiers in Environmental Science. https://doi.org/10.3389/fenvs.2019.00146.

[26] Huq, S. 2008. Community-Based Adaptation. Tiempo: A Bulletin on Climate and Development, IIED (68) July 2008.

[27] IPCC (Intergovernmental Panel on Climate Change), ed. 2001. Climate Change 2001: Mitigation. Cambridge, UK, Cambridge University Press.

[28] Kalinda, T., Samuel B., Augustine M, and Hyde H. (2008). Use of Integrated Land Use Assessment (ILUA) Data for Environmental and Agriculture Policy Review and Analysis in Zambia. Lusaka, ZM. Zambia Forestry Department Ministry of Tourism and Environment and Natural Resource.

[29] Korovulavula, I., Nunn, P.D., Kumar, R. \& Fong, T. (2019). Peripherality as key to understanding opportunities and needs for effective and sustainable climate-change adaptation: a case study from Viti Levu Island, Fiji. Climate and Development (2019). Government Printers. United NatiPresshttps://ourworldindata.org/employment-in-agriculture.

[30] Makondo, C, and David T. (2018). Climate Change Adaptation: Linking Indigenous Knowledge with Western Science for Effective Adaptation. Environmental Science \& Policy 83 (91): 1462-9011. https://doi.org/10.1016/j.envsci.2018.06.014.

[31] McNamara, K. E, Clissold, R., Westoby, R. (2020). An assessment of community-based adaptation initiatives in the Pacific Islands. Nature Climate Change. https://doi.org/10.1038/s41558-020-0813-1

[32] Murphree, M. (2000). Community-based conservation: old ways, new myths and enduring challenges, African Wildlife Management in the New Millennium, Mweka, Tanzania: College of African Wildlife Management.

[33] Miyaguchi T. (2011). Community-based adaptation to climate change: the concept, challenges, and way forward. An Environmental Journal for the Global Community (2011), 5: 21-35

[34] Mirembe, D. P. (2015). The Threat Nets Approach to Information Systems Security Risk Analysis. Ph.D. thesis, University of Groningen. https://core.ac.uk/download/pdf/232484916.pdf

[35] Moyo, B. Z. (2010). The Use and Role of Indigenous Knowledge in Small- Scale Agricultural Systems in Africa: The Case of Farmers in Northern Malawi. Ph.D. thesis, University of Glasgow. https://eleanor.lib.gla.ac.uk/record=b2775465.

[36] Mohan G, S. K. (2000). Participatory development and empowerment: the dangers of localism. Third World Quarterly 21(2): 247-268.

[37] Mulemba, H. (2009). Agriculture: Future Scenarios for Southern Africa: The Livestock Sector in Zambia and Rising Food Prices. Winnipeg, CA: International Institute for Sustainable Development.

[38] Naess, L.O. (2013). The Role of Local Knowledge in Adaptation to Climate Change. WIREs Climate Change 4 (2): $99-106$. https://doi.org/10.1002/wcc.204.

[39] Nunn, P.D. \& Kumar, R. (2019). Measuring peripherality as a proxy for autonomous community coping capacity: a case study from Bua Province, Fiji Islands, for improving climate change adaptation. Social Sciences, 8, 1-26 (2019).

[40] Nyong, A., Francis A., and Balgris O.E. (2007). The Value of Indigenous Knowledge in Climate Change Mitigation and Adaptation Strategies in the African Sahel. Mitigation and Adaptation Strategies for Global Change 12 (5): 787-797. https://doi.org/10.1007/s11027-007-9099-0.

[41] Oates, J. Briony. (2006). Researching Information Systems and Computing. London: Sage Publications. OECD (Organization for Economic Cooperation and Development) and FAO (Food and Agriculture Organization). 2017. Agricultural Outlook 2017-2026. Paris: OECD Publishing House.

[42] Onyutha, C. (2018). African Food Insecurity in a Changing Climate: The Roles of Science and Policy. Food Energy Security 8 (1). https://doi.org/10.1002/fes3.160.

[43] Rashid, M. (2009). Climate Change Vulnerability in Bangladesh: Strategic Position of DSK/DCA in the Field of Climate Change Adaptation Initiatives in Bangladesh. Dhaka, BD: Dustha Shastha Kendra.

[44] Rahman, MD. Mahmudur. (2016). Transformation in Development Planning Frameworks for Promotion of Sustainable Development of Agriculture in Bangladesh. Ph.D. thesis, Western Sydney University. https://researchdirect.westernsydney.edu.au/ islandora/object/uws:38505/datastream/PDF/view.

[45] Rahman A, Rabbani G, Mallick D, Haider N. (2012). Community-Based Adaptation: Early Learnings from CBA Conferences. Bangladesh Center for Advanced Studies (BCAS).

[46] Hannah R, Mozaharul A, Berger R, Cannon T, Huq, S and Milligan A. (2009). Community-based Adaptation to Climate Change: An Overview, in Community-based Adaptation to Climate Change', Participatory Learning and Action (PLA) Series, no. 60, International Institute for Environment and Development (IIED), pp. 11-33ctical use to local communities. Furthermore, where data is-that-mitigation-has-failed. (Accessed March 29, 2021)

[47] Roser, M. (2013). Employment in Agriculture. Our World in Data.

[48] Sabates-Wheeler R, Mitchell T, Ellis F. (2008). Avoiding Repetition: time for CBA to engage with the livelihoods literature?. IDS Bulletin 39(4): 53-59.

[49] Shafiee-Jood, M, and Ximing C. (2016). Reducing Food Loss and Waste to Enhance Food Security and Environmental Sustainability. Environmental Science \& Technology 50 (16): 8432-8443. https://doi.org/10.1021/acs.est.6b01993.

[50] Sakapaji S. C. (2021). Advancing Local Ecological Knowledge-Based Practices for Climate Change Adaptation, Resilience- Building, and Sustainability in Agriculture: A Case Study of Central and Southern Zambia. The International Journal of Climate Change: Impacts and Responses 13 (2): 61-83. doi:10.18848/1835-7156/CGP/v13i02/61-83.

[51] Smit B \& Skinner W., Mark. (2002). Mitigation and Adaptation Strategies for Global Change 7(1):85-114 DOI:10.1023/A:1015862228270 
[52] Stern, N. (2007). The Economics of Climate Change. London. Cambridge University Tweheyo, Roberty. 2018. Indigenous Knowledge and Food Security: Enhancing Decisions of Rural Farmers. Ph.D. diss., University of Groningen. https://pure.rug.nl/ws/portalfiles/ portal/61240200/Complete_thesis.pdf.

[53] UNDP (United Nations Development Program). (2019). Human Development Report 2019 Beyond Income, Beyond Averages, Beyond Today: Inequalities in Human Development

[54] Van de Ven, H. Andrew. (2007). Engaged Scholarship: A Guide for Organizational and Social Research. New York: Oxford University Press.

[55] Wiebe, K., Timothy B. S., Daniel M, and Mark W. R. (2017). The Effects of Climate Change on Agriculture and Food Security in Africa. In A Thriving Agricultural Sector in a Changing Climate: Meeting Malabo Declaration Goals through Climate-Smart Agriculture, edited by Alessandro De Pinto and John M. Ulimwengu, 5-21. Washington, DC: International Food Policy Research Institute.

[56] World Bank. (2018). The World Bank Annual Report. Washington DC: World Bank.

[57] Yohannes, H. (2016). A Review on Relationship between Climate Change and Agriculture. Journal of Earth Science \& Climate Change 7 (2): 335. https://doi.org/10.4172/2157-7617.1000335.

[58] ZCSO (2018). Livestock and Agriculture Census Summary Report. Zambia Central Statistical Office (ZCSO) 